\title{
Contextualization of basic sciences in technological degrees
}

\author{
María Teresa López-Díaz \\ Department of Mathematics \\ Universitat Politècnica de Catalunya \\ Barcelona, Spain \\ maria.teresa.lopez.diaz@upc.edu
}

\author{
Marta Peña \\ Department of Mathematics \\ Universitat Politècnica de Catalunya \\ Barcelona, Spain \\ marta.penya@upc.edu
}

\begin{abstract}
This Research-to-Practice Work in Progress paper presents a project based on increasing the motivation and performance of undergraduate technology students. It is well known that in order to achieve greater motivation for technology students, it is advisable to contextualize the basic sciences through immediate applications to the disciplines of technological degrees. The work presented is aimed at improving the teaching of sciences at a polytechnic university, illustrating their teaching through technological problems. To this end, since the 2017/2018 academic year, a seminar of contextualization of Mathematics in technological degrees addressed to the teaching staff is being held, dealing in each session with different technological areas. With the aim of assessing this seminar, anonymous surveys for teachers have been conducted. As a result, a set of practical exercises and guidelines with concepts of the different disciplines of engineering have been created. Subsequently, the material extracted from those sessions have been adapted to be useful for the students, starting in the present academic year a seminar addressed to undergraduate students. These sessions intend to improve the motivation and involvement of students, as well as to evaluate through student surveys, the achievement of mathematical and technological concepts, in order to use these results for a future adaptation of Mathematics core subjects. At the same time, during this academic year, the seminar has been expanded to Physics, starting with sessions aimed to teachers. In the future it is planned to follow the experiences with other basic sciences.
\end{abstract}

Keywords-Student engagement, Academic performance, STEM, Mathematics, Engineering, Motivation

\section{INTRODUCTION}

There has always been a great concern about which contents of Mathematics and other basic sciences are essential for technological disciplines and the methodology of teaching them to show students in the first-year courses, how important and necessary they are [1].

At the present time this concern has increased owing to the fact that European undergraduate students have fewer interest in STEM (Sciences, Technology, Engineering, Mathematics) disciplines [2]. Thus, the engineering education community work to identify the factors that cause this fact, as indicates [3].

Moreover, high occupancy demands for STEM disciplines are expected [4]. As technological knowledge and expertise is getting more specialized and economically more important, more and more jobs in the STEM domain are needed and this demand is expected to further increase in the upcoming years, as remarked in [5].

STEM disciplines are considered essential for the economic development of technological societies. As exposed in [2], the potential negative economic impact of undersupply is of concern particularly at policy level, due to opportunity costs and loss of competitiveness compared to other regions of the world, particularly South Asia, where a huge number and proportion STEM graduates are the norm.

The decreasing interest in STEM disciplines is mainly due to the low motivation of the students to Mathematics and other basic sciences in the first courses of technological degrees, which derived in most cases, from the lack of awareness of the importance of these sciences in the technological degree they have chosen and in their future profession. At the same time, this low interest in the basic sciences has as a result a high failure rate in the first courses of technological degrees.

One of the factors that have gained a special interest in academic research is the worrying dropout in higher education. The National Center for Educational Statistics (NCES) found that approximately one-third of entering college students leave higher education without obtaining a degree, especially during their first year [6].

Undergraduate students' dropout rate increases in STEM careers as can be observed in statistics of [7].

The high failure rate in the first courses means that students have not attained their academic objectives, entailing the loss of students engagement [8], which leads in most cases to the dropout in first courses of the degrees they initially have chosen, as is indicated in [8,9] and particularly analyzed in [10] for STEM degrees. Thus, to reduce dropout in the early stages of studies is necessary to promote student engagement, which is directly related to motivation [10], student achievement [11] and to academic performance [12]

In the other hand, several studies have focused on the importance of students' sense of class belonging in the improvement of students' motivation and engagement [13, 14]. This fact is specially outstanding in technological degrees, as concludes [15], belonging, then, is not just something immutable that students bring into the classroom that is resistant to change, but instead, appears to be a more malleable construct that is strongly linked to engagement and can potentially be as strong a contributor to persistence in STEM fields as self-efficacy and intrinsic interest in these fields.

Focusing on STEM degrees, it is certainly known that practical and real applications used in basic sciences encourage student engagement and motivation [10], as has been developed in previous studies $[16,17]$.

The main objective of the present work, as undertaken in similar works like [18], is to achieve greater motivation for technology students by contextualization of basic sciences (Mathematics, Physics, Chemistry, etc.) through immediate applications to the disciplines of technological degrees (Engineering, Computer Science, Architecture, etc.).

This work includes the revision of the contents and pedagogic methods of basic sciences and the improvement of motivation and engagement of students through the 
connection of these basic sciences with technological disciplines and with technological professions.

The study has been conducted at Universitat Politècnica de Catalunya, a public university of higher education in the fields of engineering, architecture, science and technology.

\section{Methodology}

During the 2017/2018 academic year the seminar "Contextualization of Mathematics in technological degrees" was inaugurated at Universitat Politècnica de Catalunya, promoted by the Vice-Rector's Office for Academic Policy.

This is the third academic year this seminar is held, which is addressed to the teaching staff and whose aim is to illustrate the applications of Mathematics in the different technological areas of engineering, architecture, computer science, etc.

The material originating from this project has been compiled, for introduction and use in the university community. In particular, exercises that are contextualized to the degree where they are taught, motivating for the student, and guidelines with notions of the different areas of engineering where they are applied, that serve as support for the teaching staff of Mathematics.

Following the successful experience with Mathematics, in the present academic year, the seminar of contextualization has been expanded to Physics creating the seminar "Contextualization of basic sciences in technological degrees at Universitat Politècnica de Catalunya". The work of "Contextualization of basic sciences in technological degrees" consists of seminaries which deal with the different basic sciences in the first courses of technological degrees (Mathematics, Physics, Chemistry, Computing, Statistics, etc.).

Firstly, these seminars have consisted of teaching lectures (monthly sessions, one hour and a half each session) for the teaching staff. Subsequently, according to the results achieved in the previous seminaries for teachers, the teaching addressed to undergraduate students is undertaken (weekly sessions, two hours each session).

It is important to highlight, as innovation in the 2019/2020 academic year, the teaching of sessions addressed to undergraduate students about "Applications of Mathematics in Engineering". This seminar intend to bring to the classroom the material extracted from the previous seminar, in order to improve academic performance and reduce the dropout rate in Universitat Politècnica de Catalunya, promoting that students feel identified with the profession they have chosen and find that everything they learn is useful for their future career. These are voluntary sessions, which are counted on European Credit Transfer and Accumulation System (ECTS) for attendees.

In order to evaluate this experience, anonymous surveys have been conducted, both for teachers and for students, of each one of the sessions. These questionnaires analyze the impact of the experience at all levels and collect the evaluations of all project members, which will be used to fit the contents of basic sciences to the needs of undergraduate students in the next academic years.

\section{RESULTS}

The project is developed in several phases, each of them deal with one of the basic sciences.
In the first phase, the project focused on Mathematics, which started in the 2017/2018 academic year and continues currently.

The second phase has followed with Physics and this seminar has started in the current academic year. It is planned to continue with the other basic sciences.

The previous sessions were addressed to the teaching staff, and this academic year the sessions addressed to undergraduate students focused in Mathematics have started.

\section{A. Contextualization of Mathematics in technological degrees}

The seminar focused on Mathematics consists of sessions focused in the different engineering disciplines (Electricity, Automatic, Mechanic, Electronic, etc.). In each one of these ambits, practical engineering cases are exposed and explained using the mathematical tools which are necessary to solve them.

For example, in Electricity area, different exercises in electrical engineering are developed: circuit analysis, alternating current, circulant matrix, etc. To study and solve these exercises, mathematical concepts and techniques need to be applied: linear system equations, complex numbers, matrix modelling, etc., as [19] shows. In this case, these mathematical tools are contextualized in different sections of Electricity.

Following this structure, the other engineering disciplines have been organized, as [20] and [21] show.

Up to the present, there have been fifteen sessions of the seminar of contextualization of Mathematics. Title and date are detailed in TABLE I.

TABLE I. SEMINAR OF CONTEXTUALIZATION OF MATHEMATICS IN TECHNOLOGICAL DEGREES

\begin{tabular}{|c|l|c|}
\hline \multicolumn{2}{|c|}{ Seminar of Contextualization of Mathematics in technological } \\
degrees
\end{tabular}




\begin{tabular}{|c|l|c|}
\hline 12 & $\begin{array}{l}\text { "Modelling and Linear Ordinary Differential } \\
\text { Equations Systems" }\end{array}$ & $10 / 04 / 2019$ \\
\hline 13 & $\begin{array}{l}\text { "Determined linear systems for consecutive } \\
\text { values of states" }\end{array}$ & $02 / 05 / 2019$ \\
\hline 14 & $\begin{array}{l}\text { "Mathematical concepts and tools in } \\
\text { Automatic" }\end{array}$ & $22 / 05 / 2019$ \\
\hline 15 & "Animated Mathematics" & $16 / 10 / 2019$ \\
\hline
\end{tabular}

During this academic year two more sessions of the seminar of contextualization of Mathematics are programmed, which are indicated in TABLE II.

TABLE II. SEMINAR OF CONTEXTUALIZATION OF MATHEMATICS IN TECHNOLOGICAL DEGREES (PROGRAMMED SESSIONS)

\begin{tabular}{|c|l|c|}
\hline \multicolumn{2}{|c|}{ Seminar of Contextualization of Mathematics in technological } \\
degrees \\
Session & \multicolumn{1}{|c|}{ Title } & Date \\
\hline 16 & $\begin{array}{l}\text { "Probability and Communication Theory: } \\
\text { Codification, Random Routes in Networks } \\
\text { and Algorithms" }\end{array}$ & $16 / 04 / 2020$ \\
\hline 17 & $\begin{array}{l}\text { "Cryptography: the arithmetic of large } \\
\text { numbers" }\end{array}$ & $19 / 05 / 2020$ \\
\hline
\end{tabular}

As an example of the activities of the seminars and in order to show the structure of a session, the second conference "Network flows" is summarized below.

This session consists of the exposition of real and practical examples of engineering, which can be understood by undergraduate students in the first-year courses, who still do not have great technological knowledge. The examples, development and Linear Algebra concepts from the session "Network flows" are detailed in TABLE III.

TABLE III. SESSION 2 OF THE SEMINAR OF CONTEXTUALIZATION OF MATHEMATICS IN TECHNOLOGICAL DEGREES: NETWORK FLOWS

\begin{tabular}{|c|l|l|}
\hline \multicolumn{3}{|c|}{ Network flows } \\
\hline Examples & \multicolumn{1}{|c|}{ Development } & \multicolumn{1}{|c|}{$\begin{array}{c}\text { Linear Algebra } \\
\text { concepts }\end{array}$} \\
\hline $\begin{array}{c}\text { Roundabout } \\
\text { traffic }\end{array}$ & $\begin{array}{l}\text { Study of the roundabout } \\
\text { operation in function of the } \\
\text { vehicles which go in and out } \\
\text { and the internal distribution. }\end{array}$ & $\begin{array}{l}\text { Matrices and } \\
\text { determinants. } \\
\text { Equations systems. }\end{array}$ \\
\hline $\begin{array}{c}\text { Electrical } \\
\text { network }\end{array}$ & $\begin{array}{l}\text { Analysis of the current } \\
\text { distribution verifying }\end{array}$ & $\begin{array}{l}\text { Equations systems. } \\
\text { Vectorial spaces. } \\
\text { Kectorial subspaces. } \\
\text { Kinchinoar applications. }\end{array}$ \\
\hline Bus station & $\begin{array}{l}\text { Study of the distribution of } \\
\text { buses in function of the } \\
\text { different movements among } \\
\text { stations. }\end{array}$ & $\begin{array}{l}\text { Discrete linear } \\
\text { systems: contagious } \\
\text { matrix, eigenvectors } \\
\text { and eigenvalues. }\end{array}$ \\
\hline $\begin{array}{l}\text { Google: webs } \\
\text { classification }\end{array}$ & $\begin{array}{l}\text { Analysis of how webs are } \\
\text { placed in function of their } \\
\text { connectivity. }\end{array}$ & $\begin{array}{l}\text { Discrete linear } \\
\text { systems: contagious } \\
\text { matrix, eigenvectors } \\
\text { and eigenvalues, } \\
\text { Gould accessibility } \\
\text { index. }\end{array}$ \\
\hline
\end{tabular}

\section{B. Contextualization of Physics in technological degrees}

Considering the success of the seminar of contextualization of Mathematics, it has been extended to
Physics, starting in the 2019/2020 academic year with sessions aimed to the teaching staff. Up to now two sessions have been held, which are detailed in TABLE IV.

TABLE IV. SEMINAR OF CONTEXTUALIZATION OF PHYSICS IN TECHNOLOGICAL DEGREES

\begin{tabular}{|c|l|c|}
\hline \multicolumn{3}{|c|}{ Seminar of Contextualization of Physics in technological degrees } \\
\hline Session & \multicolumn{1}{|c|}{ Title } & Date \\
\hline 1 & $\begin{array}{l}\text { Inaugural session 2019/2020 academic year: } \\
\text { "Etnophysics: popular statements of Physics" }\end{array}$ & $29 / 10 / 2019$ \\
\hline 2 & $\begin{array}{l}\text { "Necessity for breaking the frontiers of } \\
\text { Physics: a successful experience at } \\
\text { Universitat Politècnica de Catalunya" }\end{array}$ & $20 / 11 / 2019$ \\
\hline
\end{tabular}

During this academic year two more sessions of the seminar of contextualization of Physics are programmed, which are indicated in TABLE $\mathrm{V}$.

TABLE V. SEMINAR OF CONTEXTUALIZATION OF PHYSICS IN TECHNOLOGICAL DEGREES (PROGRAMMED SESSIONS)

\begin{tabular}{|c|l|c|}
\hline \multicolumn{3}{|c|}{ Seminar of Contextualization of Physics in technological degrees } \\
\hline Session & \multicolumn{1}{|c|}{ Title } & Date \\
\hline 3 & $\begin{array}{l}\text { "Physics for Engineering: description of } \\
\text { reality or myth of the cave" }\end{array}$ & $23 / 04 / 2020$ \\
\hline 4 & "Physics and Architecture" & $07 / 05 / 2020$ \\
\hline
\end{tabular}

With the aim of being profitable in the future, the sessions of both seminars of contextualization of basic sciences in technological degrees have been recorded, so that they can be consulted and used by the teaching staff of Mathematics/Physics and Engineering departments. These recordings are available in the repository of Universitat Politècnica de Catalunya.

\section{Applications of Mathematics in Engineering}

The material derived from these lectures has been adapted to be useful for the students. Thus, starting in the 2019/2020 academic year, weekly sessions have been taught for undergraduate students on "Applications of Mathematics in Engineering", the first semester focusing on Linear Algebra and the second semester focusing on Multivariable Calculus. This seminar has been devised to increase student engagement, motivation and involvement in the early stages of studies. In addition to the benefits and motivations of these sessions, Universitat Politècnica de Catalunya recognizes with 1 ECTS credit for each semester of attendance for students.

The sessions addressed to undergraduate students are organized in the different concepts of Linear Algebra and Multivariable Calculus in the first and in the second semester respectively. In each of these sessions mathematical concepts are developed and exercises illustrating the use of these concepts in different engineering areas are explained. This enables the students to discover which topics they need to learn in order to solve real technical problems. Thus, theory and practice are integrated and motivation is enhanced.

The first semester sessions "Applications of Mathematics in Engineering I" addressed to undergraduate students, based on Linear Algebra, are detailed in TABLE VI. 
TABLE VI. APPLICATIONS OF MATHEMATICS IN ENGINEERING I: LINEAR ALGEBRA

\begin{tabular}{|c|c|c|}
\hline \multicolumn{3}{|c|}{ Applications of Mathematics in Engineering I: Linear Algebra } \\
\hline Session & Title & Date \\
\hline 1 & $\begin{array}{l}\text { "Complex numbers on the study of price } \\
\text { fluctuations" }\end{array}$ & $02 / 10 / 2019$ \\
\hline 2 & $\begin{array}{l}\text { "Complex numbers on the study of } \\
\text { alternating current" }\end{array}$ & $09 / 10 / 2019$ \\
\hline 3 & "Indeterminate systems: control variables" & $23 / 10 / 2019$ \\
\hline 4 & $\begin{array}{l}\text { "Homogeneous indeterminate systems: } \\
\text { solutions in a vector space" }\end{array}$ & $06 / 11 / 2019$ \\
\hline 5 & $\begin{array}{l}\text { "Addition and intersection of vector } \\
\text { subspaces in discrete dynamic systems" }\end{array}$ & $13 / 11 / 2019$ \\
\hline 6 & "Linear applications and associated matrix" & $20 / 11 / 2019$ \\
\hline 7 & $\begin{array}{l}\text { "Modelling with linear ordinary differential } \\
\text { equations systems" }\end{array}$ & $27 / 11 / 2019$ \\
\hline 8 & "Base changes" & $04 / 10 / 2019$ \\
\hline 9 & $\begin{array}{l}\text { "Eigenvalues, eigenvectors and } \\
\text { diagonalization in Engineering" }\end{array}$ & $11 / 12 / 2019$ \\
\hline 10 & $\begin{array}{l}\text { "Connectivity matrix, Gould accessibility } \\
\text { index" }\end{array}$ & $18 / 12 / 2019$ \\
\hline
\end{tabular}

Likewise, the second semester sessions "Applications of Mathematics in Engineering II" based on Multivariable Calculus which have been held until now, are indicated in TABLE VII.

TABLE VII. APPLICATIONS OF MATHEMATICS IN ENGINEERING II: MULTIVARIABLE CALCULUS

\begin{tabular}{|c|c|c|}
\hline \multicolumn{3}{|c|}{$\begin{array}{l}\text { Applications of Mathematics in Engineering II: Multivariable } \\
\text { Calculus }\end{array}$} \\
\hline Session & Title & Date \\
\hline 1 & $\begin{array}{l}\text { "Discontinuous phenomena with hysteresis: } \\
\text { heartbeat, gravitational machine, sociological } \\
\text { disruptions, etc." }\end{array}$ & $25 / 02 / 2020$ \\
\hline 2 & $\begin{array}{l}\text { "Bifurcations of equilibrium points: } \\
\text { Catastrophe Theory by René Thom; the cusp } \\
\text { of Thom" }\end{array}$ & $03 / 03 / 2020$ \\
\hline 3 & $\begin{array}{l}\text { "Series development (power, Fourier): Euler } \\
\text { arc, Zeeman machine, etc." }\end{array}$ & $10 / 03 / 2020$ \\
\hline 4 & "Inverse theorem: robotic arm" & $17 / 03 / 2020$ \\
\hline 5 & "Implicit theorem: control mechanisms" & $24 / 03 / 2020$ \\
\hline
\end{tabular}

\section{Results Analysis}

The material developed in these seminars will be analyzed considering the results of the anonymous questionnaires conducted to teachers and students.

Teachers' questionnaires evaluate the contents and applications of each conference, as well as the speaker clarity and the organizational aspects of the activity. Moreover, there is the possibility to comment about the seminars, with the aim of obtaining more information about the profits of this material to increase the motivation of students in technological degrees.

Students' surveys analyze the degree of achievement of mathematical and technological concepts. With the results obtained it is planned to introduce the most illustrative applications in the core subjects of the different degrees of Universitat Politècnica de Catalunya.

In this work, we evaluate some results regarding teachers' participation. The number of teachers which have attended to the sessions undertaken to this time (15 sessions of the seminar of contextualization of Mathematics and 2 sessions of the seminar of contextualization of Physics) is 444 (among them, around 150 different teachers), what means an average of 26 teachers per session.

Teachers' questionnaires of the sessions which have held until now have been already analyzed. The participants in these surveys have been 244 teachers (55\% of the assistants to the sessions). The participants have answered three questions which must be valued on a 5-point scale $(1=$ Strongly disagree, $5=$ Completely agree). In TABLE VIII the questions and the mean results are detailed.

TABLE VIII. TEACHERS' SURVEYS ANALYSIS

\begin{tabular}{|c|c|}
\hline Survey question & Mean \\
\hline My assessment of academic aspects is positive & 4,56 \\
\hline My level of satisfaction regarding the speaker is positive & 4,62 \\
\hline General organization of the activity has been appropriate & 4,56 \\
\hline
\end{tabular}

The response of the participating teachers in these sessions has been very positive. Moreover, it is worth mentioning some teachers' comments expressed in the surveys, such as:

"Mathematical contents exposed are useful as a resource for the classes and as a salutary lesson to find other profitable examples."

"Very interesting works and very linked to social needs."

"Problems explained are innovative and have real applications."

"Practical examples, which show with clarity mathematical concepts of Linear Algebra and have applications in different fields."

\section{CONCLUSIONS AND FUTURE WORK}

The implementation of these material in basic sciences in first-year courses of technological degrees will let undergraduate students understand that these subjects are essential tools in technological disciplines and in their future professions. Thus, students' motivation for these subjects will increase and their performance is expected to improve.

This work serves as an analysis and as a starting point to the extension and generalization of the experience in the future. Moreover, following with the successful results of Mathematics and Physics, it is planned to tackle other basic sciences (Chemistry, Computing, Statistics, etc.).

Not only university teachers have shown a great interest in this project, but also secondary school teachers, who have suggest to expand it to pre-university education.

\section{ACKNOWLEDGMENT}

The authors thank Professor Josep Ferrer for his dedication and his contribution to this work. His knowledge and experience have meant a great support to this project. 


\section{REFERENCES}

[1] G. Lusa, "History, engineering and commitment" ("Historia, ingeniería y compromiso"), Universitat Politècnica de Catalunya, pp. 149-208, pp. 327-377, 2018.

[2] A. Joyce, "Stimulating interest in STEM careers among students in Europe: supporting career choice and giving a more realistic view of STEM at work," Education and Employers Taskforce Research Conference, London, England, 2014.

[3] R. M. Marra, K. A. Rodgers, D. Shen, and B. Bogue, "Leaving engineering: a multi-year single institution study," Journal of Engineering Education, vol. 101, no. 1, pp. 6-27, 2012.

[4] M. Caprile, R. Palmén, P. Sanz, and G. Dente, "Encouraging STEM Studies for the Labour Market," Directorate General for Internal Policies, 2015.

[5] J. Vennix, P. den Brok, and R. Taconis, " Do outreach activities in secondary STEM education motivate students and improve their attitudes towards STEM?," International Journal of Science Education, vol. 40, no.11, pp. 1263-1283, May 2018.

[6] E. M. Bradburn and C. D. Carroll, "Short-term enrollment in postsecondary education: student background and institutional differences in reasons for early departure," Report No. NCES 2003153, Washington, DC: National Center for Educational Statistics, U.S. Department of Education, pp. 1996-1998, November 2002.

[7] Indicators of undergraduate students' academic performance, 1.5 Education dropout rate, Ministry of Science, Innovation and Universities (Indicadores de rendimiento académico de estudiantes de grado, 1.5 Tasas de abandono del estudio, Ministerio de Ciencia, Innovación y Universidades), http://estadisticas.mecd.gob.es/EducaJaxiPx/Tabla.htm?path=/Univers itaria/Indicadores/Series_hasta_2019/Grado//10/\&file=Abandono_Gra do_Tot.px\&type $=$ pcaxis $\& \mathrm{~L}=0$.

[8] G. D. Kuh, T. M. Cruce, R. Shoup, J. Kinzie, and R. M. Gonyea, "Unmasking the effects of student engagement on first-year college grades and persistence," The Journal of Higher Education, vol 79, no. 5, pp. 540-563, 2008.

[9] V. Tinto, "Dropout from higher education: a theoretical systhesis of recent research," Review of Educational Research, vol. 45, no. 1, pp. 89-125, 1975.

[10] J. A. Gasiewski, M. K. Eagan, G. A. Garcia, S. Hurtado, and M. J. Chang, "From gatekeeping to engagement: a multicontextual, mixed method study of student academic engagement in introductory STEM courses," Research in Higher Education, vol. 53, no. 2, pp. 229-261, 2012.

[11] M. M. Handelsman, W. L. Briggs, N. Sullivan, and A. Towler, "A measure of college student course engagement," The Journal of Educational Research, vol. 98, no. 3, pp. 184-192, 2005.

[12] T. Floyd-Smith, D. Wilson, R. Campbell, N. Veilleux, R. Bates, et al., "A multi-institutional study of connection, community and engagement in STEM education: conceptual model development," In Proceedings of the ASEE (American Society for Engineering Education) Conference, Arlington, VA, June 2010.

[13] S. Zumbrunn, C. McKim, E. Buhs, and L. R. Hawley, "Support, belonging, motivation, and engagement in the college classroom: a mixed method study," Instructional Science, vol. 42, no. 5, pp. 661684, September 2014.

[14] T. M. Freeman, L. H. Anderman, and J. M. Jensen, "Sense of belonging in college freshmen at the classroom and campus levels," The Journal of Experimental Education, vol. 75, no. 3, pp. 203-220, 2007.

[15] D. Wilson, D. Jones, F. Bocell, J. Crawford, M. J. Kim, et al., "Belonging and academic engagement among undergraduate STEM students: a multi-institutional study," Research in Higher Education, vol. 56, no. 7, pp. 750-776, 2015.

[16] A. Cárcamo, J. Gómez, and J. Fortuny, "Mathematical modelling in engineering: a proposal to introduce linear algebra concepts," Journal of Technology and Science Education, vol. 6, no. 1, February 2016.

[17] G. W. T. C. Kandamby, "Enhancement of learning, through field study," Journal of Technology and Science Education, vol. 8, no. 4, May 2018.

[18] D. López, "Using service learning for improving student attraction and engagement in STEM studies," 45th SEFI Conference, Azores, Portugal, 2017.

[19] J. Ferrer, M. Peña, and C. Ortiz, "Learning Engineering to Teach Mathematics," $40^{\text {th }}$ ASEE/IEEE Frontiers in Education Conference, Washington, 2010.

[20] J. Ferrer, M. Peña, and C. Ortiz, Learning automation to teach mathematics, Automation, ISBN 9789535106852, 2012.

[21] M. Peña, "Applying Dynamical Discrete Systems to Teach Mathematics," ATINER's Conference Paper Proceedings Series EMS2017-0110, Athens, Greece, 2018. 